\title{
O Campesinato Brasileiro: uma história de resistência
}

\author{
Maria de Nazareth Baudel Wanderley ${ }^{1}$
}

Resumo:Arepresentaçãodaagriculturabrasileiraassociadaagrandes propriedades monocultoras e agroexportadoras é fruto de uma "amnésia social" que nega a contribuição do campesinato para a sociedade. Definido como uma forma social de produção, ao campesinato corresponde a um modo de vida e à uma cultura. É necessário, pois, compreender as estratégias fundiárias, produtivas e familiares que favoreceram, no Brasil, a ocupação de espaços precários e provisórios ou a criação efetiva de comunidades camponesas com maior perenidade. A modernização da agricultura no século XX provocou a expulsão dos moradores e dos posseiros. Com a redemocratização, os movimentos sociais rurais reinscrevem no debate da sociedade a atualidade da questão fundiária e a pertinência das lutas pela terra. Os recentes debates teóricos e políticos a respeito das categorias "campesinato" e "agricultura familiar" confirmaram a constituição de um setor de agricultores não patronais e não latifundiários, que exercitam formas próprias de viver e trabalhar, confirmada pelos dados do Censo Agropecuário de 2006. Os estabelecimentos agrícolas economicamente mais precários foram considerados, inicialmente, como uma "franja periférica", enquanto os programas territoriais os incorporaram na condição de "pobres do campo". A inclusão produtiva que corresponde a este tipo de agricultor deveria considerar sua histórica resistência como camponeses.

Palavras-chaves: Campesinato, agricultura familiar, pobreza rural, desenvolvimento rural.

Abstract: The representation of Brazilian agriculture, associated with large monocultures
and agroexport farms is the result of a "social amnesia" that denies the contribution of
the peasantry to society. Defined as a social production form, the peasantry represents a
way of life and a culture. It is necessary to understand agrarian, productive and familiar
strategies that favored, in Brazil, the occupation of precarious and temporary spaces or
the effective creation of rural communities with greater durability. The modernization of
agriculture in the twentieth century led to the expulsion of residents and squatters. With
democratization, rural social movements re-inscribe the debate about the relevance of the

1. Professora aposentada da Unicamp. Professora colaboradora do PPGS/UFPE. Bolsista do CNPq. E-mail: nazarebw@gmail.com 
land issue and the pertinence of land struggles. The recent theoretical and political debates about the categories "peasantry" and "family farm" confirmed the formation of a sector of non-employers and non-landlords' farmers, who exercise their own ways of living and working, confirmed by data from the last Agricultural Census (2006). The most economically disadvantaged establishments were initially considered as a "peripheral fringe", while territorial programs have incorporated them in the condition of "rural poor". The inclusive production that corresponds to this type of farmer should consider its historical resistance like peasants.

Key-words: Peasantry, family agriculture, rural poverty, rural development.

Classificação JEL: Q19.

\section{Introdução}

Não raramente, a representação socialmente construída da agricultura brasileira a associa a grandes propriedades monocultoras, produzindo para os mercados internacionais, sobre a base de um moderno e sofisticado padrão tecnológico ${ }^{2}$. O exemplo mais expressivo, nos dias de hoje, que é frequentemente veiculado nos meios de comunicação, é o das grandes plantações de soja nas antigas regiões de fronteira agrícola do País. Na monótona e monocolorida paisagem da planície, máquinas possantes vencem o tempo e o espaço e diluem da imagem qualquer presença humana.

$\mathrm{Na}$ verdade, esta representação é fruto de uma "amnésia social" (MOTTA e ZARTH, 2008) que marcou, desde suas origens, a história do campesinato no Brasil, e que nega o reconhecimento de sua contribuição para a sociedade. $\mathrm{O}$ presente texto se filia a uma outra concepção, segundo a qual

[...] o campesinato, forma política e acadêmica de reconhecimento conceitual de produtores familiares, sempre se constituiu, sob modalidades e intensidades distintas, um ator social da história do Brasil. Em todas as expressões de suas lutas sociais, seja de conquista de

2. A primeira parte deste artigo foi publicada na China e na Inglaterra, como capítulo de um livro sobre as mudanças sociais nos países Brics (WANDERLEY, 2011, 2013). espaço e reconhecimento, seja de resistência às ameaças de destruição ao longo do tempo e em espaços diferenciados, prevalece um traço comum que as define como lutas pela condição de protagonistas dos processos sociais (HISTÓRIA SOCIAL DO CAMPESINATO, 2008/2009) $)^{3}$.

Antes, porém, de expor esta argumentação, será necessário explicitar o que se pode entender por campesinato. Numa perspectiva geral, o campesinato corresponde a uma forma social de produção, cujos fundamentos se encontram no caráter familiar, tanto dos objetivos da atividade produtiva - voltados para as necessidades da família - quanto do modo de organização do trabalho, que supõe a cooperação entre os seus membros. A ele corresponde, portanto, uma forma de viver e de trabalhar no campo que, mais do que uma simples forma de produzir, corresponde a um modo de vida e a uma cultura.

Naturalmente, esta caracterização é bastante genérica e, assim apresentada, pode ser adequada à compreensão de uma grande diversidade de situações concretas de reprodução dos camponeses. Importa, assim, compreender as especificida-

3. A Coleção História Social do Campesinato, composta, até o presente momento, de nove livros publicados entre 2008 e 2010, dedica-se ao estudo das diversas dimensões do campesinato. As passagens aqui citadas são da Apresentação Geral, assinada pelos membros do Conselho Editorial da Coleção e se encontra em todos os seus volumes. 
des de cada uma destas situações, que lhes dão conteúdo social particular.

No caso do campesinato do Brasil, é preciso considerar que a agricultura brasileira, na qual ele está historicamente inserido, manteve, mesmo longamente após o fim do período colonial, seus traços estruturantes, que consistiam na grande propriedade monocultora e no trabalho escravo.

Este fato indiscutível não impediu, no entanto, que se constituíssem, nos interstícios internos e externos dos latifúndios, espaços que escapavam, de direito ou de fato, da ocupação pelos senhores da terra e que eram, sob formas distintas, usados produtivamente por pequenos agricultores camponeses. Pode-se, assim, afirmar que as particularidades acima referidas resultam das estratégias de resistência camponesa ao modo como se estruturou a atividade agrícola no país, desde seus primórdios, sob o domínio dos grandes empreendimentos e de sua capacidade de criar espaços para uma outra agricultura, a de base familiar e comunitária.

Longe, portanto, de negar a existência do campesinato, no Brasil, trata-se de compreender, em cada caso, as estratégias - fundiárias, produtivas e familiares - e a amplitude desta capacidade de iniciativa que, dependendo das circunstâncias concretas, pode oscilar entre a possibilidade de negociar, de forma subalterna e assimétrica, a ocupação de espaços precários e provisórios e a criação efetiva de raízes mais profundas de modo a estabelecer, no longo prazo, comunidades camponesas com mais perenidade.

\section{As formas precárias de acesso à terra: a posse precária e o sistema de morada}

A legislação fundiária colonial, de origem portuguesa, que perdera legitimidade com a independência nacional, em 1822, só foi substituída em 1850, criando, assim, um lapso de tempo em que apenas vigorava a posse efetiva da terra. Este "vazio" jurídico favoreceu, naquela ocasião, a ocupação precária destas terras, isto é, sem titu- lação jurídica, por pequenos agricultores, que nelas produziam para o consumo próprio, mas também para o mercado.

$\mathrm{O}$ "sistema de posse" não se extingue com a Lei de Terras de 1850, porque as grandes propriedades, localizadas, desde o início da colonização, em áreas próximas ao litoral, deixavam, nas regiões mais distantes, grandes espaços, não apropriados juridicamente, que também podiam ser ocupados por camponeses "posseiros".

Outro sistema de acesso precário à terra consistia na instalação de famílias de trabalhadores, em uma pequena área ("sítio"), no interior das fazendas - de cana de açúcar, de café etc - autorizada pelos próprios proprietários, onde podiam cultivar alguns produtos alimentares em volta da casa de moradia. O trabalhador, no entanto, era obrigado a trabalhar na cultura principal, recebendo ou não um pagamento monetário complementar, sob a forma de salário. Naturalmente, o uso da terra estava condicionado ao vínculo de trabalho com o patrão, não havendo nenhuma garantia quanto à sua continuidade (ANDRADE, 1964).

A ambivalência da situação de moradores e colonos suscitou um grande debate em todo o país: trabalhadores ou camponeses? O que ocultava este tipo de relação? Para o proprietário, sem dúvida, esse sistema era apenas uma forma de recrutamento de mão de obra, com reduzidos custos monetários, uma vez que transferia para o próprio trabalhador o ônus de sua subsistência. Para os "moradores" ou "colonos", como eram respectivamente chamados nas zonas canavieiras do Nordeste, especialmente de Pernambuco e nas zonas de produção de café em São Paulo, esta era a única via de acesso, mesmo em condições extremamente precárias, à terra e à possibilidade de organização de uma base produtiva de caráter familiar, que permitia a cultura de produtos de subsistência, cujo excedente podia ser, eventualmente, destinado ao mercado (PALMEIRA, 1977).

É importante registrar que há uma grande diversidade de modalidades de cessão precária da terra, que variam de um máximo de subordinação do trabalhador às demandas de trabalho 
das grandes propriedades a um grau de autonomia, que permite assegurar mais dedicação ao sítio familiar. Os moradores nordestinos utilizam as categorias de "sujeitos" e "libertos" para indicar estas distinções, como revela Afrânio Raul Garcia Jr (1983, 1990).

Além destas formas principais de acesso precário à terra, a pequena propriedade é também uma realidade significativa no campo brasileiro. Ela é particularmente importante na região Sul, onde tem sua origem na política de concessão de um pequeno lote de terra aos migrantes estrangeiros, especialmente alemães, italianos e poloneses, que se instalaram na região, a partir do século XIX. Mas ela sempre existiu, sobre a base de distintas relações sociais em todas as regiões do país (QUEIROZ, 1963, 1973; CANDIDO, 1964). Em São Paulo, com a crise do café dos anos 1930, cafeicultores endividados venderam parte de suas propriedades em pequenos lotes, que, em muitos casos, foram adquiridos por produtores não proprietários. Mais recentemente, também merecem especial referência os chamados "produtores integrados", isto é, aqueles que se tornam fornecedores de produtos agropecuários para as agroindústrias, situação predominante no Sul do País (FERREIRA, 1995; PAULILO, 1990).

Em todos esses casos, a propriedade formalmente reconhecida favorece a consolidação de uma economia camponesa mais "liberta", isto é, menos dependente dos grandes proprietários, no que se refere ao acesso à terra. A tensão entre subordinação e autonomia se desloca, no entanto, para o âmbito da comercialização dos produtos, onde os camponeses sofrem as consequências de relações também subordinadas e assimétricas.

\section{A modernização da agricultura: descampesinização e campesinização}

A partir dos anos 1960, assiste-se no Brasil à emergência de profundas transformações no setor agrícola e no meio rural. No bojo destas mudanças, está o processo de modernização da agricultura que, aqui, assume duas dimensões centrais e complementares. Em primeiro lugar, a subordinação da atividade agrícola às exigências dos setores dominantes da indústria e do capital financeiro, que se traduziu, fundamentalmente, pela adoção de máquinas, equipamentos e insumos de origem industrial nos processos da produção agrícola (SILVA, 1981, 1982; KAGEYAMA, 1996; DELGADO, 1985). Em segundo lugar, a ocupação das fronteiras agrícolas por grandes empresas, que se beneficiaram de políticas públicas de incentivo a essa expansão.

Nos dois casos, as consequências sobre os espaços de reprodução dos pequenos agricultores camponeses são diretas e imediatas. As grandes propriedades expulsaram massivamente os trabalhadores residentes em seu interior, passando a contratá-los apenas nos momentos de necessidade de trabalho. Isso foi possível porque a modernização da produção agrícola afetou de forma diferenciada os diversos momentos do processo produtivo (SILVA, 1981). Enquanto as fases de preparo da terra e de cuidados com a plantação foram mecanizadas e impulsionadas pelo uso de insumos modernos, a colheita permanecia, na maioria das culturas, como uma atividade manual. Não havia, portanto, mais razão para o proprietário reter, em suas terras, a mão de obra durante todo o ano.

Esse processo de expulsão será tanto mais intenso, quanto os patrões temiam as consequências da promulgação do Estatuto do Trabalhador Rural (Lei n. 4.214, de 02 de março de 1963) - primeiro texto legal que reconheceu os trabalhadores como sujeitos de direitos trabalhistas, passíveis de serem reclamados em justiça - pelo movimento sindical que nascia e se fortalecia na mesma ocasião.

Sem o recurso da produção de subsistência, o trabalhador, expulso do campo, perde os pressupostos mínimos da condição camponesa e passa a viver nas periferias degradadas das cidades, de onde procura ocupação, agora, sem nenhum vínculo, nas colheitas que se sucedem ao longo do ano, num amplo espaço que pode ser, inclusive, inter-regional.

Os camponeses não sofreram passivamente os efeitos deste processo de expulsão. Além do 
movimento sindical, já referido, é exatamente neste período, que surgem em Pernambuco as primeiras organizações das Ligas Camponesas que, espalhando-se em seguida em várias regiões do país, expressam suas demandas em termos de uma reforma agrária, que significasse a real e efetiva distribuição de terras (JULIÃO, 1962). Uma demanda claramente camponesa.

Por sua vez, a integração econômica das fronteiras agrícolas ao modelo econômico dominante resultou na deflagração de conflitos pela terra e na também massiva desarticulação das tradicionais relações de posse, predominantes nestas regiões. Fragilizados pela ausência de titulação jurídica de suas posses, os camponeses sofrem as consequências da concentração fundiária, que é a face mais aparente do capital que se impõe por meio de grandes empresas agropecuárias (ESTERCI, 1987). É por esta razão que a modernização agrícola brasileira é denominada "conservadora" (SILVA, 1982). Ela provoca - de uma certa forma, paradoxalmente - um movimento de luta pela terra, que se estende por todas as regiões do país, porém, e mais intensamente, no Norte e no Centro-Oeste (MARTINS, 1981). Em 1980, um documento da Conferência Nacional dos Bispos do Brasil (CNBB), intitulado "A Igreja e os problemas da terra", denuncia com veemência a "extrema violência da luta pela terra em nosso país, com características de uma guerra de extermínio, em que as baixas mais pesadas estão do lado dos lavradores pobres" (CNBB, 1980).

Escrevendo no início dos anos 1980, José de Souza Martins afirma que "hoje, no Brasil, a questão política no campo é, principalmente, a questão da propriedade da terra" (MARTINS, 1982, p. 11). No mesmo sentido, Leonilde Sérvolo de Medeiros identifica, como traço comum a todos os movimentos sociais rurais, neste período, "a resistência dos trabalhadores rurais, fossem posseiros, arrendatários, foreiros ou moradores, em deixar a terra em que trabalhavam e da qual estavam sendo expulsos" (MEDEIROS, 1989, p. 34). Por esta razão, a luta pela terra se dissemina ao ponto de que, como afirma esta autora, "não houve, na década de 70, um único estado da Federação onde a luta pela terra não estivesse presente, de forma mais ou menos aguda" (MEDEIROS, 1989, p. 110).

O momento da redemocratização, que se institucionaliza com o fim dos governos militares e a promulgação da Constituição de 1988, significou a (re)emergência dos movimentos sociais, que puderam, assim, construir publicamente suas análises da realidade brasileira, em oposição às visões até então dominantes e impositivas e formular suas demandas políticas e suas estratégias de luta. Da mesma forma, o Estado também inicia um processo de democratização em suas diversas instâncias, que o torna mais apto a acolher as demandas da sociedade, amparadas nos novos preceitos constitucionais.

No que se refere ao meio rural, é fundado, em 1984, o Movimento dos Trabalhadores Rurais sem Terra (MST). Por sua vez, o Movimento Sindical Rural, que existia desde o início dos anos 1960, se fortalece, então, sob a liderança da Confederação Nacional dos Trabalhadores na Agricultura (Contag). São estes movimentos, cada um a seu modo, que reinscrevem no debate da sociedade, a atualidade da questão fundiária e a pertinência das lutas pela terra pelos camponeses expropriados ou com pouca terra.

Os marcos dessas lutas nesses períodos são o Estatuto da Terra (Lei n. 4.504, de 30 de novembro de 1964) - promulgado na vigência do primeiro governo militar - e, posteriormente, o I Plano Nacional da Reforma Agrária, lançado em 1985. Progressivamente, multiplica-se o número de assentamentos rurais. O maior número foi implantado na década de 1990, durante o Governo de Fernando Henrique Cardoso, sob o efeito das pressões dos movimentos de luta pela terra (MEDEIROS, 1989, 1994, 1999; BERGAMASCO e NORDER, 1996; SCHMIDT, MARINHO e ROSA, 1998; MARTINS, 2003; LEITE, 2004).

Não resta dúvida que a ideologia conservadora dos governos militares, bem como suas práticas autoritárias e repressivas, favoreceram a consolidação do modelo da modernização conservadora no Brasil. Com a redemocratização, foi possível introduzir no debate da sociedade 
novas ideias e propostas de novos modelos de agricultura. O ponto de partida dessa discussão, eminentemente política, é o reconhecimento de que as unidades familiares de produção não são incompatíveis com o desenvolvimento agrícola, isto é, de que são capazes de transformar seus processos de produção, no sentido de alcançar novos patamares tecnológicos, que se traduzam pela maior oferta de produtos, maior rentabilidade dos recursos produtivos aplicados e a plena valorização do trabalho. Esta afirmação atinge diretamente o argumento central que justificava o apoio irrestrito e exclusivo, dado no Brasil à grande propriedade, considerada como a única em condições de modernizar o setor agrícola e ao modelo de modernização "produtivista" que foi apoiado pelo Estado.

\section{Conceituação do campesinato: uma disputa política por reconhecimento}

A compreensão do que seja um campesinato no Brasil continua a ser objeto de um amplo debate e de acirradas disputas políticas, que envolve, entre outros, pesquisadores acadêmicos, formuladores de política e os distintos movimentos sociais. Está em questão o lugar social destes agricultores, que se expressa por meio do significado que se atribui às categorias "campesinato", "agricultura familiar" e "agronegócio".

No Brasil, a referência ao campesinato assume dupla conotação. Por um lado, o campesinato corresponderia, para muitos, às formas mais tradicionais da agricultura, realizadas em pequena escala, dispondo de parcos recursos produtivos, pouco integrado ao mercado e à vida urbana e frequentemente identificado à incivilidade e ao atraso econômico e social. Neste sentido, ele se distinguiria da agricultura familiar, a qual, apesar de ter também condições de produção restritas, estaria mais integrada às cidades e aos mercados. Por outro lado, a palavra "camponês" carrega um forte conteúdo político, pois ela é frequentemente associada ao movimento camponês, que foi duramente perseguido, como "subversivo" pelos governos militares, que dirigiram o Brasil de 1964 a 1985. A busca de uma expressão politicamente mais "neutra" levou, nesse período, a que fossem adotadas, oficialmente, denominações como "pequenos produtores", "agricultores de subsistência", "produtores de baixa renda" que, além de imprecisas, carregavam um forte conteúdo depreciativo.

Nos anos 1990, a categoria "agricultura familiar" foi adotada pelo próprio Estado, ao formular um vasto programa de apoio aos agricultores (Pronaf), cuja atividade estivesse organizada pela e para a família (ABRAMOVAY, 1998; ABRAMOVAY e VEIGA, 1999; MATTEI, 2005). Com isso, diluía-se o conteúdo histórico-político que a palavra "camponês" inspirava, ao mesmo tempo em que se afirmava, pela primeira vez, o reconhecimento da condição de produtor agrícola e uma valoração positiva de suas particularidades. Atualmente, ela é consagrada, não só pelas instituições do Estado, mas também pelos próprios atores sociais, seus beneficiários.

A respeito do Pronaf, Maria José Carneiro considera que

[...] a proposta de um programa de fortalecimento da agricultura familiar voltado para as demandas dos trabalhadores - sustentado em um modelo de gestão social em parceria com os agricultores familiares e suas organizações - representa um considerável avanço em relação às políticas anteriores. Tal tentativa de ruptura é intencional e explícita no próprio texto do Pronaf, quando ele chama a si o desafio de construir um novo paradigma de desenvolvimento rural para o Brasil sem os vícios do passado (CARNEIRO, 1997, p. 70).

Os agricultores familiares são ainda percebidos, por alguns, como integrantes das principais culturas agropecuárias do País, inclusive das grandes cadeias produtivas globalizadas. Neste caso, eles são incluídos na categoria genérica do "agronegócio", juntamente com os grandes proprietários e empresários do setor agrícola do País. Esta corrente, ideologicamente mais ligada a este 
mesmo setor, considera o agronegócio em sua dimensão estritamente econômica, capaz de gerar interesses comuns a todos aqueles que, de uma forma ou de outra, são agricultores. Negam-se, assim, as dimensões identitárias que nutrem as categorias "camponês" e "agricultor familiar", retirando delas toda referência à constituição de sujeitos políticos e, frequentemente, desconhecendo o caráter subalterno de sua participação setorial, que exclui qualquer possibilidade de adesão econômica e política à grande propriedade e à grande produção.

Nos dias atuais, percebe-se a revalorização das categorias "camponês" e "campesinato". Isso ocorre, sobretudo, no interior dos próprios movimentos sociais, que as associam à profunda crítica aos processos da modernização conservadora e à crescente valorização das práticas agroecológicas.

As novas proposições e ações coletivas por uma agricultura diferente se apóiam fortemente nas críticas das noções de modernidade e de modernização, esboçando os contornos de uma outra modernização, que repousa nas noções e significações de "coletivo" e de "comunidade/local" (ALMEIDA, 1999, p. 33).

De fato, grupos cada vez mais numerosos de camponeses se organizam, em todas as regiões, com o objetivo de afirmar a autonomia dos agricultores familiares, considerando-os portadores de uma experiência camponesa, que os torna capazes de assumir, sob outros moldes, o progresso da agricultura e do meio rural brasileiros.

Todas as críticas portam em si uma ideia central e dominante que é a de preservar uma certa categoria social e produtiva na agricultura: o camponês, o pequeno agricultor/produtor ou, ainda, o agricultor familiar e, por conseguinte, a necessidade de reorientar os sistemas produtivos e as tecnologias empregadas na direção de um reforço na capacidade econômica e de autonomia dessa categoria (ALMEIDA, 1999, p. 58).

Parece-nos, portanto, evidente que, mais do que recortar campos distintos, com denomina- ções particulares, atribuindo a cada um características excludentes e, mesmo antagônicas em relação aos demais, deve-se atentar para a constituição de um vasto campo de agricultores não patronais e não latifundiários que, como foi dito acima, exercitam formas próprias de viver e trabalhar no mundo rural. Esse conjunto se caracteriza por uma grande diversidade de situações concretas, que geram múltiplas identidades, com distintas relações com a cidade, com o mercado e com o Estado (HISTÓRIA SOCIAL DO CAMPESINATO, 2008/2010).

Assim sendo, mais importante é perceber que, apesar da heterogeneidade referida, todas estas situações concretas apontam para a existência, no meio rural brasileiro, de produtores agrícolas, vinculados a famílias e grupos sociais que se relacionam em função da referência ao patrimônio familiar e constroem um modo de vida e uma forma de trabalhar, cujos eixos são constituídos pelos laços familiares e de vizinhança. É a presença desta característica que nos autoriza a considerá-los camponeses, para além das particularidades de cada situação e da conexão (ou superposição) das múltiplas referências identitárias, assumindo que os conceitos de campesinato e agricultura familiar podem ser compreendidos como equivalentes.

\section{Perfil atual da agricultura familiar no Brasil}

Para além das divergências conceituais, outra grande dificuldade consiste em quantificar este universo de agricultores familiares camponeses. Até recentemente, as estatísticas oficiais não dispunham de critérios que permitissem distinguir as unidades familiares do conjunto dos estabelecimentos agrícolas. Para superar a imprecisão das categorias adotadas, os pesquisadores formulavam exercícios de aproximação, mais ou menos bem sucedidos, que variam ao sabor das concepções teóricas de cada um e das restrições das informações disponíveis. Assim, ainda nos anos 1970, a pesquisa realizada sob a coordenação de 
José Graziano da Silva adotou o pressuposto de que a produção camponesa estaria concentrada nas faixas de área até 50 hectares, informação mais objetiva, disponível no Censo Agropecuário de 1970. A partir deste recorte, os referidos autores puderam perceber a

[...] importância das formas da pequena produção no conjunto da produção agropecuária. Essa importância se revela em três planos: no número de pessoas envolvidas, tanto pelo seu valor absoluto, como em comparação com o que deveria representar a forma dominante de trabalho sob o desenvolvimento do capital, ou seja, o assalariamento; em termos geográficos, isto é, da ocorrência generalizada dessas formas em praticamente todas as regiões estudadas; e, finalmente, na sua contribuição no produto gerado (SILVA, 1978, p. 240).

Posteriormente, Sonia Bergamasco e Angela Kageyama, analisando os dados do Censo Agropecuário de 1980, construíram uma tipologia dos agricultores familiares, entendidos enquanto aqueles que utilizam mão de obra familiar, em sua atividade produtiva. Segundo estas autoras, os estabelecimentos familiares correspondiam a $71,6 \%$ do total dos estabelecimentos e se diferenciavam internamente em empresas familiares que contratam trabalhadores permanentes, estabelecimentos familiares complementados por empregados temporários e os familiares puros, sem trabalhador externo à família (BERGAMASCO e KAGEYAMA, 1990).

Baseando-se nos Censo Agropecuário de 1996, um estudo, realizado pela FAO, em cooperação com o Ministério do Desenvolvimento Agrário, coordenado por Carlos Guanzirolli, formulou uma nova metodologia para apreender o perfil da agricultura familiar no Brasil (GUANZIROLLI et al., 2001). De acordo com esta abordagem, de um total de 4.859 .732 estabelecimentos agrícolas, 4.139 .369 são estabelecimentos familiares, o que corresponde a $85,2 \%$.

Esta pesquisa confirmou a contribuição marcante da agricultura familiar. Apesar de não dispor dos recursos produtivos comparáveis aos alocados ao setor patronal, esta forma de agricultura revela uma grande capacidade produtiva. Do conjunto dos agricultores familiares, que ocupa 30,5\% da área total, $75 \%$ são proprietários de áreas que, para a grande maioria, não ultrapassam os cinco hectares. É nessas exíguas e insuficientes áreas que a agricultura familiar chega a absorver 76,9\% do pessoal ocupado na atividade agrícola em todo o País e produz o equivalente a $37,9 \%$ do valor bruto da produção agropecuária nacional, beneficiando-se, apenas, de $25,3 \%$ dos financiamentos destinados à agricultura.

Só recentemente, o IBGE, em cooperação com o Ministério do Desenvolvimento Agrário (MDA), elaborou para o último Censo Agropecuário de 2006 uma grade de variáveis, que permitiu, pela primeira vez, introduzir a categoria de estabelecimentos familiares em seus levantamentos (IBGE, 2006; FRANÇA et al., 2009). Essa categoria é também definida levando em consideração pressupostos teóricos e condicionamentos operacionais: ela se baseou nas concepções adotadas pela Lei da Agricultura Familiar (Lei n. 11.326/2006, Art. 3º), que considera as exigências de que o produtor:

I - não detenha, a qualquer título, área maior do que 4 (quatro) módulos fiscais;

II - utilize predominantemente mão de obra da própria família nas atividades econômicas do seu estabelecimento ou empreendimento;

III - tenha renda familiar predominantemente originada de atividades econômicas vinculadas ao próprio estabelecimento ou empreendimento;

IV - dirija seu estabelecimento ou empreendimento com sua família.

Segundo esses dados, havia naquela data, em todo o País, um total de 4.367.902 estabelecimentos familiares, definidos, segundo os critérios legalmente fixados, nos termos acima indicados, o que correspondia a $84,4 \%$ do total dos estabelecimentos agropecuários. Essas unidades de produção familiares possuíam 80,25 milhões de hectares, equivalentes a $24,3 \%$ da área total.

Tal como já indicavam as conclusões dos estudos anteriores, os novos dados reiteram que 
a agricultura familiar permanece significativamente responsável pela produção de alimentos no Brasil. Com efeito, provém deste setor, entre outros bens: $87 \%$ da produção de mandioca; $70 \%$ do feijão, $58 \%$ do leite, $46 \%$ do milho, $38 \%$ do café, $34 \%$ do arroz, bem como, $59 \%$ do rebanho de suínos, $50 \%$ dos efetivos avícolas e $30 \%$ do gado bovino.

Para realizar essa intensa e diversificada atividade, os estabelecimentos familiares ocupam um grande contingente de trabalhadores: 12,3 milhões de pessoas, correspondentes a $74,4 \%$ do total do pessoal ocupado na agricultura brasileira. Destes, $90 \%$ constituíam a força de trabalho familiar. O Censo de 2006 confirma, assim, mais uma vez, o peso dessa forma de produção, ao mesmo tempo em que revela os limites de sua reprodução, subordinada que está à perpetuação da concentração fundiária, marca da história da agricultura e do mundo rural brasileiros. Cerca de metade dos estabelecimentos familiares está localizada na região Nordeste, onde representam $89 \%$ dos estabelecimentos agrícolas da região.

\section{A pobreza rural}

Estes dados, no entanto, não podem ofuscar a forte e continuada incidência de situações de pobreza, inclusive da pobreza extrema no meio rural brasileiro.

São numerosos os estudos que tentam quantificar a pobreza rural, utilizando, para isso, critérios distintos. Como exemplo, o documento que integrou O Mapa da Fome, elaborado em 2003, tomou como parâmetro o valor da cesta básica familiar para definir o número de famílias cuja renda não é suficiente para adquiri-la (PELIANO, 1993). Por este critério, cerca de $32 \%$ dos brasileiros (aproximadamente 54 milhões de pessoas) foram considerados pobres.

O Programa Fome Zero, implantado durante o primeiro Governo de Luiz Inácio Lula da Silva, construiu uma metodologia que procurou definir o "público vulnerável à fome". Usando como base o valor de um dólar por dia per capita, que é a linha de pobreza definida pelo Banco Mundial, os autores do Programa definiram o público beneficiário do mesmo como "aquela parcela da população que não possui renda suficiente para garantir sua segurança alimentar, estando, portanto, vulnerável à fome" (SILVA, BELIK e TAKAGI, 2001, p. 70). As conclusões deste estudo apontam para

[...] um público potencial beneficiário de 44,043 milhões de pessoas, pertencentes a 9,324 milhões de famílias. Esta população pobre representa $21,9 \%$ das famílias e $27,8 \%$ da população total do país, sendo $19,1 \%$ da população das regiões metropolitanas, $25,5 \%$ das áreas urbanas não metropolitanas e 46,1\% da população rural. Em termos absolutos, representam, respectivamente: 9.003 milhões, 20,027 milhões e 15,012 milhões, para cada área de residência (p. 74).

Estes dados revelam com clareza que, embora não corresponda ao maior número de pobres do país, a pobreza que se manifesta nas áreas rurais é, relativamente, a mais expressiva, uma vez que atinge quase a metade da população do campo. Estudos recentemente elaborados atestam que os programas de transferência de renda adotados nos últimos governos, para as populações mais pobres, têm conseguido alterar esta realidade, provocando significativos aumentos dos níveis de renda e redução da desigualdade social.

Também crescem hoje no Brasil as abordagens sobre a pobreza que incorporam outras dimensões econômicas e sociais, para além da dimensão exclusivamente monetária. Segundo Ângela Kageyama e Rodolfo Hoffmann,

A noção de pobreza refere-se a algum tipo de privação, que pode ser somente material ou incluir elementos de ordem cultural e social, em face dos recursos disponíveis de uma pessoa ou família. Essa privação pode ser de natureza absoluta, relativa ou subjetiva (KAGEYAMA e HOFFMANN, 2006, p. 80)

Os referidos autores formularam uma classificação de "pobres e não pobres", objetivando 
“considerar a pobreza não apenas pela baixa renda, mas também pela privação de bens essenciais, cuja disponibilidade depende em parte de gastos públicos" (KAGEYAMA e HOFFMANN, 2006 , p. 83). Com base nesses critérios, reiteram a constatação de que "o Nordeste e a zona rural continuam a ser os grandes 'depósitos' da pobreza no Brasil" (KAGEYAMA e HOFFMANN, 2006, p. 97).

Recentemente, os textos publicados pelo Instituto Interamericano de Cooperação para a Agricultura (IICA) sobre essa questão oferecem um conjunto de análises sobre o que é considerado "a nova cara da pobreza rural" (IICA, 2006, $2007,2012 b$ e 2013). Dentre esses estudos, Claudio Salvadori Dedecca et al. referem-se à "necessidade de se analisar a pobreza numa perspectiva multidimensional, que alargasse o enfoque centrado na visão monetária do problema, isto é, da relação estreita entre necessidade básica de renda e pobreza" (DEDECCA et al., 2012, p. 17) Com o objetivo de subsidiar as políticas sociais, os referidos autores estabeleceram seis dimensões consideradas relevantes: "inserção no mercado de trabalho, renda familiar corrente, acesso à terra, acesso à educação, perfil demográfico das famílias e condições de vida" (DEDECCA et al., 2012, p. 29).

O que é importante considerar em todas estas análises é que se trata, fundamentalmente, da pobreza gerada como consequência direta do modelo de desenvolvimento rural prevalecente na sociedade brasileira e da forma como foi implantada no Brasil a moderna agricultura. Para José Graziano da Silva,

Muito se tem falado e escrito sobre o "notável" desempenho do ponto de vista produtivo da nossa agropecuária nessas décadas passadas, especialmente na crise dos anos 80 . Mas, pouco se fala sobre o resultado do ponto de vista social desse modelo de crescimento agroindustrial excludente que aumentou ainda mais a concentração da renda e a proporção de pobres no campo. E quase nada se tem escrito sobre o que fazer com os excluídos, os "barrados do baile", os descamisados, ou os pobres do campo ou qualquer outro nome que se dê a essa verdadeira população sobrante, marginal do ponto de vista das necessidades internas de acumulação do sistema (SILVA, 1995, p. 127).

\section{7. "Franja periférica", "pobres do campo", "camponeses": olhares distintos, políticas diferenciadas}

A partir do final dos anos 1980, forma-se, progressivamente, um amplo consenso, no sentido da necessidade de inclusão social deste vasto setor reconhecido como agricultura familiar. Consenso que deixa, no entanto, uma larga margem ao debate e às escolhas políticas dissonantes quanto a questões centrais: quem são estes agricultores? Como compreender sua diversidade? Quais políticas devem ser implementadas para apoiá-los social e economicamente? As categorias "franja periférica", "pobres do campo" e "camponeses" condensam o sentido das divergências que se cruzam ao longo do tempo.

\subsection{A franja periférica}

O estudo FAO/Incra (1994), acima referido, distinguiu, num total de 7 milhões de estabelecimentos, quatro categorias: patronal, abrangendo 500 mil estabelecimentos; familiar consolidada, abarcando 1,5 milhão; em transição, correspondente a 2,5 milhões e periférica, somando 2,5 milhões de unidades produtivas ${ }^{4}$. Em termos proporcionais, essas categorias correspondiam respectivamente a $7,1 \%, 21,5 \%, 35,7 \%$ e $35,7 \%$ do número total dos estabelecimentos agropecuários do País.

Considerando em particular as duas últimas categorias, que totalizam 4 milhões de estabelecimentos, o referido estudo afirma:

4. O Relatório FAO/Incra constituiu o principal documento de análise e proposições que inspirou a concepção do Pronaf. 
Por falta de capacidade de autofinanciamento, pela exiguidade e fraqueza de suas terras, pela falta de capacitação de seus recursos humanos, ou por ser vítima do forte viés urbano das políticas públicas, uma importante fatia da agricultura familiar tende à degradação, seja pela migração para as cidades, seja por meio da pulverização minifundiária que gera estabelecimentos de terceira categoria (FAO/INCRA, 1994, p. 12).

Como consequência, para as ações do Estado, a pesquisa $\mathrm{FAO} /$ Incra formulou duas grandes orientações. Em primeiro lugar, considerando que seria possível estabelecer uma "zona de transição formada pela faixa mais fragilizada da agricultura familiar e pela faixa menos desvalida da grande massa de sítios periféricos", o "foco das políticas governamentais para a agricultura" deveria ser ocupado por esses agricultores "em transição" (FAO/INCRA, 1994, p. 13). Em segundo lugar, reiterando a concepção de que os "periféricos" não podem ser considerados apropriadamente como agricultores, conclui:

O grande desafio é a criação de instrumentos que gerem novas oportunidades de expansão e/ou reconversão produtiva para o maior número dos estabelecimentos que se encontrem na categoria transitória entre a "periférica" e a "familiar consolidada". Muitos desses instrumentos ajudarão a agricultura familiar em geral. Mas seria ilusão imaginar que poderiam responder também às dificuldades das cerca de 2,5 milhões de famílias que vivem em estabelecimentos totalmente marginais ( $\mathrm{FAO} /$ INCRA, 1994, p. 15).

O estudo propõe ainda que:

Parte desse último contingente, principalmente, os jovens, deverá ser beneficiada pela política de reforma agrária, como ocorreu com pouco mais de 300 mil famílias assentadas nos últimos anos. E a geração de empregos não agrícolas, de preferência rurais, bem como a prestação de serviços temporários, que surgirão da dinamização da agricultura familiar, abrirão oportunidades para os demais (FAO/ INCRA, 1994, p. 15).
Essa concepção, segundo a qual parte significativa dos estabelecimentos familiares está à margem da atividade agropecuária, foi adotada por diversos outros pesquisadores, que a qualificam como "franja periférica", "conjunto marginal de estabelecimentos" e "desvalidos". Nessa perspectiva, as famílias e os indivíduos não podem ser considerados sequer como produtores de baixa renda, visto que não possuem nenhuma renda monetária proveniente da produção agropecuária. Sua sobrevivência é assegurada por ocupações temporárias e precárias e os seus estabelecimentos constituem "mais locais de residência e subsistência de uma mão de obra desempregada ou subempregada, do que, propriamente, empresas do setor agropecuário" (FAO/INCRA, 1994, p. 12).

Consequentemente, afirma-se a impotência de medidas de política agrícola para melhorar as condições de vida e de trabalho desse segmento e se preconiza o apoio a atividades não agrícolas, capazes de absorvê-los produtivamente.

A confirmação, em termos quantitativos, da diversidade de situações, no interior do grande grupo de estabelecimentos familiares, constituiu, sem dúvida, um grande avanço naquele momento. No entanto, parece também evidente que os resultados obtidos, as análises formuladas e as propostas de política encaminhadas refletem, antes de tudo, as concepções teóricas e as escolhas metodológicas de seus autores, sobretudo, no que diz respeito às relações da agricultura familiar com o mercado, que não incorporam a valorização do autoconsumo e da autoprovisão do estabelecimento familiar e ao trabalho externo da família, visto como uma perda de substância da condição de agricultor e como se fosse uma experiência exclusiva de agricultores "periféricos". Além disso, apesar de admitir que os dados possam refletir circunstâncias conjunturais pouco favoráveis, estas não são levadas em conta na caracterização dos tipos propostos. O semiárido nordestino, por exemplo, corresponde, exatamente, a essa situação de perda, como analisa Tânia Bacelar de Araújo: 
Porque daqueles $43 \%$ da população economicamente ativa do País que vive no Nordeste, a grande parte está no espaço semiárido. E, exatamente ali, no final da década de oitenta, a única fonte de renda monetária da grande massa de pequenos produtores havia acabado. A praga do bicudo havia atingido o algodão e o desaparecimento dessa fibra tinha eliminado a única fonte de renda monetária deles (ARAÚJO, 2012, p. 22).

As conclusões desse debate inspiraram direta e imediatamente a concepção da política de apoio à agricultura familiar, que se traduziu pela implantação do Pronaf em 1995/1996 e que, sem excluir formalmente nenhuma categoria de agricultores familiares, priorizou aquela definida como "em transição". ${ }^{5}$ Os numerosos e diversos analistas desse programa governamental tendem a afirmar sua importância e os impactos positivos que provocou, ao oferecer, de modo inédito, recursos produtivos para agricultores até então sem acesso a transações bancárias.

O maior interesse do Pronaf é que, desde o início, ele não foi construído simplesmente como um programa voltado ao atendimento específico de uma necessidade setorial e de um segmento particular. Ele se apoia em duas premissas básicas, de ordem normativa. Em primeiro lugar, o Pronaf afirma não apenas as necessidades sociais, mas, e ao mesmo tempo, a viabilidade econômica de unidades produtivas cujo tamanho esteja ao alcance da capacidade de trabalho de uma família. Para um país de tradição latifundiária e escravista, formado por radicais formas de dissociação entre trabalho e propriedade, e trabalho e conhecimento, afirmar a consistência econômica da unidade entre esses termos que a História separou não é trivial. A novidade do Pronaf estava em sua intenção explícita de propiciar aumento da geração de renda dos agricultores por meio de seu acesso ao crédito bancário (ABRAMOVAY e PIKETTI, 2005, p. 58).

5. Não pretendo aqui realizar uma avaliação do Pronaf, mas apenas refletir sobre a concepção que orienta esse programa, a respeito dos agricultores familiares mais empobrecidos.
Na prática, no entanto, a universalização do crédito seria de difícil concretização para os agricultores familiares e as avaliações realizadas revelam que, já na primeira fase de sua implantação, o acesso ao crédito do Pronaf tendeu a se concentrar nos estados do Sul, especialmente entre os agricultores com vínculos contratuais de fornecimento com agroindústrias, mais aptos a oferecer as garantias exigidas pelo sistema bancário (MATTEI, 2005, p. 20).

Mesmo considerando os critérios seletivos que informaram o Pronaf em suas fases iniciais, é importante registrar todos os esforços que foram empreendidos para dotar essa política de uma maior abrangência nos planos regional e social. Assim, com o objetivo de atender amplamente os pequenos agricultores familiares, o Pronaf adotou uma diferenciação dos públicos beneficiários, distinguindo os seguintes grupos: Grupo A: constituído dos agricultores assentados da reforma agrária; Grupo B: agricultores com baixa produção e pouco potencial de aumento, no qual também estão incluídos indígenas e quilombolas. Os demais grupos, C, D e E correspondem aos produtores que dispõem de melhores níveis de renda bruta familiar ou com potencial para atingir esses índices (MATTEI, 2006, p. 5).

Essa iniciativa significava claramente o esforço do governo no sentido de ampliar o acesso dos agricultores considerados "periféricos", majoritariamente presentes nas regiões Norte e Nordeste do País. Como afirma Valter Bianchini,

[...] o Pronaf é um programa de inclusão produtiva. Como programa da agricultura familiar, ele tem responsabilidade de inclusão social, mas também de garantir condições para as famílias que já estão inseridas no mercado (BIANCHINI, 2012, p. 80).

No entanto, apesar da crescente abrangência do programa, globalmente e em sua distribuição regional, a ampliação do atendimento ao Grupo B continuava bloqueada.

Do ponto de vista do montante de recursos destinado às diversas categorias, não se obser- 
vam grandes alterações, em termos da concentração dos recursos em determinadas categorias. Assim, na safra de 1999, os agricultores enquadrados no grupo $\mathrm{D}$ respondiam por $48 \%$ do total e os do grupo C, por $22 \%$, revelando que essas duas categorias detinham cerca de $70 \%$ do total do crédito disponibilizado pelo programa. O grupo A respondia por 21\%; o grupo $\mathrm{B}$, por apenas $1 \%$ (primeiro ano de operação dessa modalidade); e o restante dizia respeito aos contratos sem enquadramento definido. Na safra agrícola de 2004, essa trajetória mudou um pouco, sobretudo pela maior participação do grupo B, que passou a responder por $7 \%$ do total, ao mesmo tempo em que o grupo D reduzia sua participação em $11 \%$ e o grupo A em $13 \%$. O grupo C aumentou sua participação para 25\% (MATTEI, 2005, p. 24).

Dessa forma, o Pronaf não conseguia evitar, mais uma vez, a imagem de um programa voltado para a camada dos agricultores familiares da região Sul, cujas condições permitiam assumir compromissos financeiros junto aos bancos. Para Aquino e Schneider,

O Pronaf apresenta dificuldades para promover mudanças no campo, porque o modelo de agricultura preconizado pelo programa está intimamente ligado com a lógica setorial e produtivista do padrão de desenvolvimento convencional. Na verdade, o estilo de agricultura familiar efetivamente privilegiado pela política de crédito do Pronaf ao longo de sua trajetória não foi aquele baseado na diversificação de atividades e fontes de renda das unidades de produção, mas o da "pequena empresa familiar" especializada em atividades agrícolas integradas às cadeias produtivas do agronegócio exportador (grupos D e E). Ora, na medida em que se adotou este estilo de agricultura familiar como referência para a ação governamental, então, naturalmente, o crédito passou a ser disponibilizado em sua maior parte para fortalecer a produção e a produtividade das monoculturas de grãos, objetivando, com isso, elevar a competitividade dos "verdadeiros agricultores familiares" escolhidos como protagonistas do desenvolvimento rural brasileiro (AQUINO e SCHNEIDER, 2010, p. 15) ${ }^{6}$.

Mauro Del Grossi, analisando os mesmos dados do Censo, observa:

Em resumo, o Censo Agropecuário mostra uma agricultura familiar diversificada, onde parte possui condições de produtividade superior à da agricultura não familiar, enquanto outra parte sobrevive em condições de renda agrícola reduzida, provavelmente, próxima à condição de pobreza (DEL GROSSI, 2012, p. 322).

\subsection{Os pobres do campo}

Em 2003, ocorrerá uma nova inflexão da trajetória das políticas públicas em relação ao atendimento dos agricultores economicamente mais fragilizados, com a implantação dos programas territoriais no âmbito do MDA. Essa nova orientação representou um salto qualitativo em relação às políticas anteriores, precisamente, no que se refere à consideração da pobreza e da desigualdade como o foco central das políticas públicas, bem como à concepção adotada e ao tratamento proposto aos agricultores, até então vistos como "periféricos".

Tânia Bacelar de Araújo analisa a origem dessa desigualdade:

Esses territórios são frágeis e concentram pobreza, pois foram abandonados no século $\mathrm{XX}$, quando o Brasil privilegiou investimentos nos grandes centros urbanos, na ânsia de se tornar potência industrial no âmbito mundial. [...] O hiato entre o Brasil urbano e a grande maioria dos Territórios rurais é uma herança do processo de desenvolvimento herdado (ARAÚJO, 2010, p. 204).

Caio Galvão de França também aponta os caminhos necessários para assegurar a redução da pobreza e das desigualdades sociais:

6. Um novo salto será dado, em 2005, com a adoção do Programa Agroamigo pelo Banco do Nordeste do Brasil, com atuação nos estados do Nordeste e no Norte de Minas Gerais (www.bnb.gov.br). 
Num cenário de continuidade de crescimento econômico com distribuição de renda, redução da pobreza e redução das desigualdades, e de avanço das políticas sociais com suas potencialidades para garantir um acesso universal aos direitos fundamentais será preciso combinar, pelo menos, duas dimensões na dinâmica da participação social e da articulação dos atores. Por um lado, produzir a força social necessária para efetivar os direitos, com as especificidades adequadas a cada segmento social e considerando as múltiplas possibilidades de acesso. Por outro lado, redesenhar novas demandas e criar as melhores condições para a sua afirmação como parte de uma agenda dirigida a aprofundar a democracia econômica e política (FRANÇA, 2010, p. 79).

Nos documentos elaborados pelo MDA observa-se claramente uma mudança de linguagem: a referência aos "pobres do campo" substitui em larga medida as expressões "periféricos", "desvalidos" e "marginais". Sob essa nova abordagem são enfocadas três dimensões complementares. Em primeiro lugar, mais do que uma mudança de linguagem, a "franja periférica" passa a ser definida como o próprio público alvo dos programas territoriais, a quem se reconhece, claramente, a condição de agricultor familiar e se destina o apoio às atividades produtivas agrícolas. Referindo-se ao Programa Territórios da Cidadania, que consideram "uma agenda democrática para o desenvolvimento rural", Caio Galvão de França e Joaquim Soriano afirmam:

[...] dois elementos foram centrais na configuração dessa agenda e das próprias condições para sua efetivação. O primeiro foi a transformação do paradigma da superação da fome e da pobreza, que tem no Projeto Fome Zero sua expressão mais acabada. O segundo foi a afirmação da identidade social da agricultura familiar e a legitimação de políticas públicas agrícolas diferenciadas (FRANÇA e SORIANO, 2010, p. 224).

Em segundo lugar, apesar de manter as categorias de renda como elemento distintivo dos grupos de beneficiários do Pronaf, os programas territoriais levam em consideração a diversidade de situações que os caracterizam: assentados, comunidades tradicionais, agricultores familiares de comunidades rurais, etc. Em terceiro lugar, o crédito rural está associado a outras políticas, que procuram apreender a complexidade da situação dos agricultores pobres.

O MDA incorporou o Pronaf aos seus programas territoriais, propondo uma atenção especial aos agricultores tipificados como Pronaf B.

Criado em 2000, no âmbito do Pronaf para combater a pobreza rural, o Microcrédito Rural (também conhecido como Grupo B do Pronaf) é estratégico para os agricultores familiares pobres, pois valoriza o potencial produtivo deste público e permite estruturar e diversificar a unidade produtiva. Pode financiar atividades agrícolas e não agrícolas geradoras de renda. São atendidas famílias agricultoras, pescadoras, extrativistas, ribeirinhas, quilombolas e indígenas que desenvolvam atividades produtivas no meio rural. Elas devem ter renda bruta anual familiar de até R\$ 10 mil, sendo que no mínimo $50 \%$ da renda devem ser provenientes de atividades desenvolvidas no estabelecimento rural (www.mda.gov.br)

Apesar da abordagem positiva e dinâmica dessa intervenção pública, não se pode desconhecer as enormes dificuldades para a implantação efetiva dos seus programas de combate à pobreza persistente. De fato, os agricultores correspondentes ao Grupo B do Pronaf continuam a exibir sinais evidentes de sua fragilidade, especialmente no que se refere ao acesso à terra e às condições de produção. São produtores que possuem uma área exígua e insuficiente para a sua atividade, quase sempre inferior a 10 hectares - a maioria concentrada no estrato de um a menos de dois hectares; em muitos casos, são não proprietários que produzem em terras alheias por meio de contratos precários e extorsivos de acesso à terra. É significativa a proporção daqueles cuja renda monetária é inferior ao salário mínimo. Essa renda é completada, sobretudo, com as trans- 
ferências proporcionadas pelas políticas sociais governamentais. Além disto, a distância em relação aos centros urbanos desfavorece o acesso a serviços essenciais e, nos locais de moradia, são críticas as condições de saneamento, do acesso à água potável, à coleta de lixo e à eletricidade.

Muitos obstáculos se interpõem, assim, inclusive, internamente às próprias estruturas dos programas territoriais. A concepção dos pequenos estabelecimentos como não agrícolas continua a ser defendida em foruns de reflexão e debate sobre o tema, influenciando fortemente a pesquisa acadêmica e as decisões dos formuladores de políticas públicas. Na verdade, o que está em questão nessa nova orientação não é apenas a redefinição de procedimentos formais que permitam ampliar a capilaridade e a abrangência dos beneficiários efetivos do sistema de crédito, mas uma nova concepção sobre as possibilidades de sua inclusão produtiva.

O Ministério do Desenvolvimento Social, em documento citado por Lauro Mattei, define a inclusão produtiva como

[...] o processo econômico e social que conduz à formação de cidadãos integrados ao mundo por meio do trabalho. Portanto, o objetivo da inclusão produtiva é proporcionar autonomia para as pessoas sobreviverem de maneira digna e sustentável tendo trabalho (MATTEI, 2012, p. 55).

Para o autor, as políticas de inclusão produtiva supõem a articulação das esferas:

[...] de acesso aos mercados de bens e serviços e de inclusão social via políticas públicas. No primeiro caso, destacam-se políticas específicas voltadas às atividades produtivas capazes de agregar valor aos produtos e ampliar o acesso aos mercados locais e regionais; e voltadas ao processo de construção de novas formas de organização da produção pautadas pelo princípio da economia familiar e solidária, por exemplo, que procuram estabelecer métodos produtivos centrados na gestão e conservação dos recursos naturais (MATTEI, 2012, p. 57).
O desafio consiste, no entanto, em definir a natureza da inclusão produtiva que deve ser proposta a este tipo de agricultor. A esse respeito, admite-se que os indivíduos, de um modo geral, demandam a ser inseridos na sociedade através do reconhecimento de sua condição de trabalhador. O lugar que assumem no mundo do trabalho constitui o elemento central que forja a sua própria identidade social. Porém, no caso que estamos aqui considerando, não se trata de um trabalho qualquer. $\mathrm{O}$ que está fortemente em questão é que tipo de trabalho corresponde à inclusão social desse trabalhador em particular. A maioria dos agricultores antes considerados "periféricos" reivindica o reconhecimento de sua identificação com um tipo de trabalho específico, aquele exercido de forma autônoma, em caráter familiar, através da posse e controle dos meios de produção necessários. Em outras palavras, inclusão social para os próprios produtores significa o reconhecimento de sua condição de agricultor, de suas formas de trabalhar e produzir, cujas potencialidades devem ser apoiadas pelas políticas públicas.

Pode-se concluir desse quadro geral que esses agricultores vivenciam situações de extrema precariedade e que têm, efetivamente, uma enorme dificuldade para gerar renda monetária de sua atividade produtiva. No entanto, não é possível desconhecer o fato, por todos afirmado, de que, apesar dos obstáculos, eles não são outra coisa senão agricultores: suas estratégias revelam os esforços empreendidos para assegurar a subsistência através dos reduzidos meios que dispõem.

Nesse e em outros contextos, os agricultores familiares expressam suas demandas enquanto produtores e, sobretudo, se definem como agricultores. Albuquerque Neto e Silva (2012) são bem claros a esse respeito:

\footnotetext{
Após perguntar aos entrevistados sobre quanto tempo faz que ele (a) é agricultor (a), escutamos quase que unanimemente as frases "sempre foram agricultor", "desde que eu me entendo de gente eu sempre fui agricultor" e "desde que nasci". Essas falas configuram um modo de vida destes agricultores, que
} 
permitem compreender uma intensa relação entre trabalho, terra e família segundo a visão de mundo destes produtores rurais (ALBUQUERQUE NETO e SILVA, 2012, p. 15).

\subsection{Camponeses}

Se a referência à categoria "franja periférica" aponta para a perda de substância da condição de agricultores, a de "pobres do campo" supõe que a superação deste estado de pobreza deve ser buscada através das mais diversas atividades não agrícolas, sem necessariamente o respaldo da centralidade da unidade de produção familiar. Em todos estes casos, as políticas públicas se distanciam das afirmações identitárias, dos próprios agricultores, que não podem ser caracterizados apenas como não produtores de renda monetária.

De fato, a adoção da renda monetária proveniente da atividade agropecuária como critério distintivo dos estabelecimentos se contrapõe ao reconhecimento das especificidades dessa agricultura familiar que se reproduz em condições particularmente hostis na realidade brasileira.

As configurações camponesas são bastante diversas, entretanto as visões correntes tendem a compreendê-las por meio de noções pré-concebidas, como a caracterização dos camponeses como praticantes de uma agricultura de subsistência e desprovidos de mecanismos de geração de renda. Assim, necessitam de intervenção exterior de modo a modernizar suas práticas agrícolas para se posicionarem no patamar de geradoras de renda e de maior inserção no mercado. Essa pré-noção, que pode ser identificada na formulação de diversos agentes como intelectuais, agências governamentais, igrejas e organizações não governamentais, não dá conta das diferentes formas de organização social, das instituições econômicas e das práticas culturais do campesinato (GODOI, MENEZES e MARIN, 2009, p. 23).

Assim como a condição de pobreza não se esgota na reduzida disponibilidade de renda monetária, expressa na relação dólar por dia, a superação da pobreza não se esgota na simples distribuição de crédito aos mais pobres. $\mathrm{O}$ acesso ao crédito deve estar inserido numa política mais ampla e completa, que considere o indivíduo ou a família que o recebe, não apenas como pobre, mas como um agricultor que, se apoiado convenientemente, tem potencialidades para assegurar, em melhores condições, a sobrevivência de sua família e participar da produção da riqueza de sua comunidade local. $\mathrm{O}$ apoio em questão diz respeito ao acesso ao conjunto dos recursos produtivos e aos bens e serviços necessários não apenas à reprodução de uma qualidade de vida considerada socialmente satisfatória, mas, sobretudo, no sentido apontado por Steven M. Helfand e Vanessa da Fonseca Pereira, da construção do "patrimônio dos pobres" (HELFAND e PEREIRA, 2012, p. 126).

Colocando-se na perspectiva dos sujeitos analisados, e não daquela ditada pelas regras do mercado, registra-se com muita frequência que as categorias familiares consideradas "em transição" e "periféricas" não hesitam em se definir como agricultores, em suas práticas presentes e em seus projetos de futuro. Para eles, a produção para o próprio consumo ou para o consumo interno do seu estabelecimento é uma prática que os legitimam como agricultores familiares. Apesar da forma subordinada e precária, sua inserção nos mercados agropecuários é reivindicada como um elemento central de suas estratégias produtivas. Se o trabalho fora do sítio familiar se impõe como uma necessidade para complementar a renda ou para encaminhar profissionalmente os filhos, ele não é percebido em contradição com as atividades agrícolas, porém, de modo articulado a essas, sob a forma de um sistema de atividades familiar, sobre o que muito ainda há a compreender. Assim, como para afirmar sua identidade de agricultores, eles têm uma experiência acumulada de estratégias e de práticas sociais, inclusive no campo produtivo, que revelam sua capacidade de sobreviver, enfrentando situações de grande precariedade, a respeito do que, no Brasil, já se dispõe de uma vasta bibliografia.

Não é demasiado insistir que as políticas é que devem responder às necessidades concretas 
do seu público alvo e não o contrário, esse adaptar-se aos condicionantes operacionais das políticas. É o que propõe Ghislaine Duque, a respeito das tecnologias que deveriam ser geradas para atender às particularidades do semiárido:

Para que a convivência com o semi-árido seja sustentável do ponto de vista econômico, as tecnologias propostas têm que ser de baixo custo e de replicação fácil pelas famílias agricultoras da região. Para que seja sustentável do ponto de vista ambiental, essas tecnologias devem ser respeitosas do meio ambiente. Finalmente, para que haja convivência socialmente sustentável, essas mesmas tecnologias devem ser frutos de um processo pedagógico e político que aproveite o saber das famílias produtoras e dialogue com elas, permitindo-lhes apropriarem-se do mesmo e difundi-lo de forma autônoma, dispensando aos poucos a presença de mediadores. Portanto, fica claro que os aspectos organizativos e educativos estão intimamente interligados com os aspectos tecnológicos (DUQUE, 2008, p. 137).

Nesse sentido, a incorporação do conceito de "camponês", tal como é analisado na vasta literatura brasileira e estrangeira, e proposta na primeira parte deste artigo, permite superar o que ainda resta de viés operacional no tratamento aos "pobres do campo".

Essa compreensão deverá servir de base para fundamentar politicamente as escolhas da sociedade a respeito dos agricultores familiares em suas distintas categorias. Em outras palavras, trata-se de justificar a opção política de oferecer apoio às demandas produtivas desses agricultores mais precarizados, que vivem hoje o pior dos dois mundos: como não são considerados produtores, acena-se com a possibilidade de acesso a empregos não agrícolas, frequentemente não rurais, os quais, por sua vez, são reduzidos ou mesmo inexistentes na maioria dos pequenos municípios e raramente são objetos de políticas específicas.

\section{Conclusões}

O futuro dos camponeses brasileiros se inscreve num contexto particularmente complexo, marcado pelas escolhas da sociedade brasileira sobre a maneira como enfrentará alguns de seus principais desafios, enquanto sociedade. Trata-se, entre outros temas, da preservação dos recursos naturais, dos desafios tecnológicos face às exigências bioéticas, ambientais e sociais, da disputa de espaços produtivos entre a produção de alimentos e de matérias-primas voltadas para a geração de energia, das relações produção-consumo associadas à garantia da qualidade dos produtos e das formas de produzir, da eliminação da pobreza extrema e da consolidação da democracia pelo reconhecimento dos sujeitos de direito que vivem no campo.

Cabe aos movimentos sociais demonstrar a sensibilidade e a firmeza para assumir a luta pela preservação de uma outra agricultura, que seja, de fato, econômica, ambiental e socialmente sustentável. E cabe à academia produzir os conhecimentos necessários, capazes de inspirar novas políticas de inclusão social, que efetivamente considere o campesinato enquanto forma de produção e modo de vida.

\section{Referências bibliográficas}

ABRAMOVAY, R. Bases para formulação da política brasileira de desenvolvimento rural: agricultura familiar e desenvolvimento territorial. Brasília, NEAD/IICA, 1998.

. e VEIGA, J. E. da. Novas Instituições para o desenvolvimento rural: o caso do Programa Nacional de Fortalecimento da Agricultura Familiar (PRONAF). Brasília, IPEA, 1999. (Texto para Discussão, 641)

ALMEIDA, J. A construção social de uma nova agricultura. Porto Alegre: UFRGS, 1999.

ANDRADE, M. C. de. A terra e o homem no Nordeste. 2. ed. São Paulo, Brasiliense, 1964.

ANJOS, F. S. dos. A agricultura familiar, pluratividade e desenvolvimento rural no Sul do Brasil. Pelotas, UFPEL, 2003. 
BERGAMASCO, S. M. P. P. e KAGEYAMA, A. A estrutura de produção no campo em 1980. Perspectivas, São Paulo, n. 12/13, 1989/1990, p. 55-72.

. e NORDER, L. A. C. O que são assentamentos rurais. São Paulo, Brasiliense, 1996. (Primeiros Passos, 301)

BRANDÃO, C. R. O afeto da terra: imaginários, sensibilidades e motivações de relacionamentos com a natureza e o meio ambiente entre agricultores e criadores sitiantes do Bairro dos Pretos, nas encostas paulistas da Serra da Mantiqueira, em Joanópolis. Campinas, UNICAMP, 1999. (Pesquisas).

BRASIL. INCRA. Livro branco da grilagem de terras no Brasil. Disponível em: www.incra.gov.br. Acesso em: 15 set. 2009.

CANDIDO, A. Os parceiros do Rio Bonito: estudo sobre o caipira paulista e a transformação dos seus meios de vida. Rio de Janeiro, José Olympio, 1964. (Col. Documentos brasileiros, 118).

CARNEIRO, M. J. Política pública e agricultura familiar: uma leitura do Pronaf. Estudos, Sociedade e Agricultura, Rio de Janeiro, n. 8, abr. 1997, p. 70-82.

. e MALUF, R. S. (Orgs.). Para além da produção; multifuncionalidade e agricultura familiar. Rio de Janeiro, Mauad, 2003.

CNBB (Conferência Nacional dos Bispos do Brasil). A Igreja e os Problemas da Terra. Itaici, fevereiro de 1980. (Documento aprovado pela 18 $8^{-}$Assembléia da CNBB em 14 de fevereiro de 1980).

COHEN, M. e DUQUÉ, G. Les deux visages du Sertão: stratégies paysannes face aux sécheresses: Nordeste du Brésil. Paris, IRD, 2001. (Collection À Travers Champs).

DEL GROSSI, M. E., SILVA, J. G. e TAKAGI, M. Evolução da Pobreza no Brasil, 1995/99. Campinas, IE/UNICAMP, 2001. (Texto para Discussão. n. 104)

DELGADO, G. C. Capital financeiro e agricultura no Brasil: 1965-1985. São Paulo, Ícone, 1985. (América Latina).

ESTERCI, N. Conflito no Araguaia; peões e posseiros contra a grande empresa. Petrópolis: Vozes, 1987.

FERREIRA, A. D. D. Agricultores a agroindústrias: estratégias, adaptações e conflitos. Reforma Agrária. Revista da ABRA, Campinas, v. 25, n. 2/3, mai./dez. 1995, p. 86-113.

. e BRANDEMBURG, A. (Org.). Para pensar outra agricultura. Curitiba, UFPR, 1998.

FRANÇA, C. G. de, DEL GROSSI, M. E. e MARQUES, V. P. M. de A. O Censo Agropecuário de 2006 e a Agricultura
Familiar no Brasil. Brasília, NEAD/MDA, 2009. (NEAD Debate).

GARCIA JR, A. Terra de trabalho: trabalho familiar de pequenos produtores. Rio de Janeiro, Paz e Terra, 1983. (Estudos sobre o Nordeste, 8).

O Sul: caminho do roçado: estratégias de reprodução camponesa e transformação social. São Paulo, Marco Zero, 1990. (Pensamento Antropológico).

GODOI, E. P. de. O trabalho da memória: cotidiano e história no Sertão do Piauí. Campinas, UNICAMP, 1999. (Pesquisas)

GUANZIROLI, C. et al. Agricultura familiar e reforma agrária no século XXI. Rio de Janeiro, Garamond, 2001.

HISTÓRIA SOCIAL DO CAMPESINATO. Apresentação geral. São Paulo, UNESP, Brasília MDA, 2008/2009. 9 volumes.

IBGE. (Instituto Brasileiro de Geografia e Estatística). Caderno da Agricultura Familiar: primeiros resultados. Disponível em: <www.ibge.gov.br>. Acesso em: 14 mar. 2011.

JULIÃO, F. Que são as ligas camponesas? Rio de Janeiro, Civilização Brasileira, 1962. (Caderno do Povo Brasileiro, 1)

KAGEYAMA, A. A. (coord.) O novo padrão agrícola brasileiro: do complexo rural aos complexos agroindustriais. In: DELGADO, Guilherme Costa; GASQUES, José Garcia; VILLA VERDE, Carlos Monteiro (Orgs.). Agricultura e políticas públicas. 2.ed. Brasília: IPEA, 1996, p. 113-223. .(IPEA, 127).

LAMARCHE, H. (Coord.). A agricultura familiar. 1. Comparação internacional: uma realidade multiforme. Campinas, UNICAMP, 1993.

- (Coord.) A agricultura familiar: 2. comparação internacional: do mito à realidade. Campinas, UNICAMP, 1998.

LEITE, S. et al. Impactos dos assentamentos: um estudo sobre o meio rural brasileiro. São Paulo, UNESP, 2004. (Estudos NEAD, 6)

MARTINS, J. de S. Os camponeses e a política no Brasil. Petrópolis: Vozes, 1981.

. Expropriação E violência; a questão política no campo. 2. ed. São Paulo, HUCITEC, 1982.

. (Coord.). Travessias: a vivência da reforma agrária nos assentamentos. Porto Alegre, Editora UFRGS, 2003, (Série Estudos Rurais). (2ª Edição em 2009). 
MATTEI, L. Impactos do PRONAF: análise de indicadores. Brasília, NEAD/MDA, 2005. (Estudos NEAD, 11).

MEDEIROS, L. S. de. História dos movimentos sociais no campo. Rio de Janeiro, FASE, 1989.

MEDEIROS, L. S. de et al. (Orgs.). Assentamentos rurais; uma visão multidisciplinar. São Paulo, UNESP, 1994.

. e LEITE, S. (Org.). A formação dos assentamentos rurais no Brasil: processos sociais e políticas públicas. Porto Alegre, UFRGS, 1999. (Estudos Rurais)

MOTTA, M. e ZARTH, P. (Orgs.). Formas de resistência camponesa: visibilidade e diversidade de conflitos ao longo da história. 1: Concepções de justiça e resistência nos Brasis. São Paulo, UNESP; Brasília, Ministério do Desenvolvimento Agrário, NEAD, 2008. (História Social do Campesinato no Brasil).

PALMEIRA, M. Casa e trabalho: nota sobre as relações sociais na plantation tradicional. Contraponto, Rio de Janeiro, v. 2, n. 2, 1977, p. 103-114.

PAULILO, M. I. S. Produtor e agroindústria: consensos e dissensos: o caso de Santa Catarina. Florianópolis. UFSC, 1990.

QUEIROZ, M. I. P. de. Uma categoria rural esquecida. Revista Brasiliense, S. Paulo, n. 45, 83-97, 1963.

O campesinato brasileiro; ensaios sobre civilização e grupos rústicos no Brasil. S. Paulo, EDUSP, Petrópolis, Vozes, 1973. (Estudos Brasileiros, 3).

REYDON, B. P. (Orgs.). Agropecuária, situação atual e perspectivas. Campinas, ABRA, 1995, p. 127-149.

SABOURIN, E. Camponeses do Brasil, entre troca mercantil e reciprocidade. Rio de Janeiro, Garamond, 2009.

SANTOS, J. V. T. dos. Colonos do vinho: estudo sobre a subordinação do trabalho camponês ao capital. São Paulo, HUCITEC, 1978. (Ciências Sociais. Realidade Social).

- Matuchos, exclusão e luta: do Sul para a Amazônia. Petrópolis, Vozes, 1993.
SCHMIDT, B. V., MARINHO, D. N. e ROSA, S. L. C. (Orgs.). Os assentamentos de reforma agrária no Brasil. Brasília, UnB, 1998.

SILVA, J. F. G. da (Coord.). Estrutura agrária e produção de subsistência na agricultura brasileira. São Paulo, HUCITEC, 1978. (Estudos Rurais)

SILVA, J. G. da. Progresso técnico e relações de trabalho na agricultura. São Paulo, Hucitec, 1981. (Economia \&Planejamento. Teses e Pesquisas).

A modernização dolorosa: estrutura agrária, fronteira agrícola e trabalhadores rurais no Brasil. Rio de Janeiro, Zahar, 1982. (Agricultura e Sociedade).

.Urbanização e pobreza do campo. IN: RAMOS, Pedro.

SILVA, J. G. da., BELIK, W. e TAKAGI, M. Projeto Fome Zero - Uma Proposta de Política de Segurança Alimentar para o Brasil. São Paulo, Instituto da Cidadania, 2001.

WANDERLEY, M. de N. B. O campesinato brasileiro: uma história de resistência. In: Bai xi nong min; Kang zheng de li shi. In: Peilin Li, M K Gorshkov, Celi Scalon, K L Sharma. Jin Zhuan Guo Jia She Hul Fen Ceng; Bian Qian Yu Bi Jiao, Beijin, Social Sciences Academic Press, 2011, p. 133-145.

. Brazilian Peasantry: a history of resistence. In: Peilin Li, M K Gorshkov, Celi Scalon, K L Sharma. Social Stratification in the BRIC Countries: Change and Perspective. London, World Scientific Publishing Co, 2013, pp. 163-183.

WILKINSON, J. Mercados, redes e valores. Porto Alegre: UFRGS, 2008.

WOORTMANN, E. F. Herdeiros, parentes e compadres: colonos do sul e sitiantes do nordeste. São Paulo, HUCITEC, 1995.

WOORTMANN, K. Com parentes não se neguceia: o campesinato como ordem moral. Brasília, UnB, 1990. (Anuário Antropológico, 87)

WOORTMANN, E. e WOORTMANN, K. O trabalho da terra: a lógica e a simbólica da lavoura camponesa. Brasília, UnB, 1997. 
